\title{
Congenital Horner's syndrome with unilateral facial flushing
}

\author{
Hiroshi Saito
}

\begin{abstract}
Two patients with congenital Horner's syndrome had unilateral facial flushing. Both showed pupillary supersensitivity to epinephrine as well as anhidrosis on the affected side of the face and neck. Facial skin temperature after exercise increased on the intact side, but decreased on the affected side. Thermal vasodilation in the major portions of the face is regulated by sympathetic vasodilator fibres, and less predominantly by adrenergic vasoconstrictor fibres. The asymmetry of facial flushing may have been caused by impaired sympathetic vasodilation and further intensified by active vasoconstriction due to supersensitivity to circulating catecholamine on the affected side.
\end{abstract}

Congenital Horner's syndrome (CHS), a rare disorder, is characterised in its fully developed form by miosis, by narrowing of the palpebral fissure, heterochromia of the iris and anhidrosis. ${ }^{1-3}$ Though impaired facial flushing in response to temperature has been described in patients with unilateral lesions of the sympathetic pathways to the face, ${ }^{45}$ the investigations on facial vasomotor function in CHS are scanty. ${ }^{26}$ Two cases of CHS had asymmetric facial flushing, and abnormal vasomotor functions of the affected side.

\section{Case reports}

In both cases, examinations revealed no abnormalities other than ophthalmological and facial autonomic functions. Hemifacial atrophy was not seen. There was no family history of any similar disorder. Routine laboratory tests and radiological examinations; brain CT, radiographs of the skull, chest or cervicothoracic spines, were normal. Angiography and myelography were not performed.

Case 1: A 21 year old female visited our clinic because of unilateral facial flushing with increased body temperature. Her delivery and neonatal history was normal. From an early age it was noted that the right pupil was smaller, and that, on crying or after bathing, there was an absence of flushing and sweating on the right side of the face. Between the ages of 12-13 years, she noticed that the brown colour of her right iris was lighter than the left. Since adolescence the asymmetry of the facial flushing had caused her occasional social embarrassment. After exercise in hot weather, the face became cooler on the right side and hotter on the left side compared with when she was resting.

Supine blood pressure was $120 / 70 \mathrm{~mm} \mathrm{Hg}$, and the heart rate 78 per minute. There was no orthostatic hypotension. There was $2 \mathrm{~mm}$ of right ptosis. The diameter of the right and left pupils under indoor illumination were 3.0 and $5.0 \mathrm{~mm}$, respectively. The right iris was lighter in colour than the left. Thirty minutes after an instillation of $1 \%$ hydroxyamphetamine, the pupillary diameter was $3.5 \mathrm{~mm}$ on the right side and $6.5 \mathrm{~mm}$ on the left. Subsequently, two drops of $1.25 \%$ epinephrine dilated the right pupil to $7.0 \mathrm{~mm}$, but had no effect on the left pupil. Her facial colour was symmetrical when she was resting. Sweating after exercise, tested by a colorimetric method, revealed an anhidrosis on the right side of the face and neck. The rest of the body sweated normally. The face flushed only on the left side. The right side of the face showed considerable blanching. Skin temperature was not measured.

Case 2: A four year old boy was referred to our clinic because of unilateral facial flushing after physical exercise or bathing. His birth was normal. His parents noted that he did not flush or sweat on the left side of his face. Otherwise, he showed normal physical and mental development. Between the age of three to four years he was teased by his play mates because of unilateral flushing. His mother commented that his right eyelid drooped when he was sleepy. His mother and younger brother had normal pupils.

His blood pressure was $112 / 60 \mathrm{~mm} \mathrm{Hg}$ and the heart rate $84 / \mathrm{min}$. There was no orthostatic hypotension. Palpebral fissure and the colour of the iris were symmetrical. When examined under indoor illumination the diameters of the right and left pupils were 4.0 and $3.0 \mathrm{~mm}$, respectively. An hour after two drops of $1.25 \%$ epinephrine were administrated, the left pupil dilated to $6.5 \mathrm{~mm}$, while the right remained unchanged. Sweating was tested in the summer months, at the ages of four and six years, by a modified colorimetric method. Sweating on exercise was absent on the left side of the face and neck. The upper extremities and trunk showed symmetric diffuse discolouration. Sweat rate including insensible transpiration ( $\mathrm{mg} / \mathrm{cm}^{2} /$ minute) was quantitatively measured by a capacitance hygrometer (HidrographAMU-2, Kyokuto-Denshi Company). After three minutes of exercise, the sweat rate of the forehead was 0.621 on the right side and 0.079 on the left. For the forearm it was $\mathbf{0 . 2 5 9}$ on the right and 0.236 on the left. The skin temperature of the cheek was measured by 
thermister thermometers (Core-Temp-CTM205, probe-No: PD-K161, Termo-Japan Company). In the resting state it was $35.2^{\circ} \mathrm{C}$ on the right side and $35 \cdot 1^{\circ} \mathrm{C}$ on the left. After three minutes of exercise, it increased to $35.9^{\circ} \mathrm{C}$ on the right but decreased to $34.4^{\circ} \mathrm{C}$ on the left. The temperature of the skin on the forearm was the same on both sides; $33.5^{\circ} \mathrm{C}$ before exercise and $34 \cdot 2^{\circ} \mathrm{C}$ after exercise.

\section{Discussion}

Both patients showed typical clinical history of congenital Horner's syndrome. Horner's eye signs were complete in case 1 , but in case 2 ptosis was absent or equivocal. In both cases, however, the pupil of the affected side was supersensitive to $1.25 \%$ epinephrine, indicating a functionally denervated pupillary dilator. Their past history, and physical and radiological examinations failed to localise the responsible lesion. The combination of eye signs and anhidrosis limited to the ipsilateral side of the face and neck indicated that the lesion must be in the vicinity of the superior cervical ganglion and the bifurcation of the common carotid artery. ${ }^{278}$ In patients with a lesion distal to the bifurcation of the common carotid artery, anhidrosis is confined to the medial part of the forehead and side of the nose. $^{8}$ Furthermore, lesions involving the stellate ganglion cause anhidrosis of the face, neck, upper extremity and the upper part of the trunk.

Heterochromia was evident in case 1 , but absent in case 2 . Weinstein et $a^{2}$ postulated that an absence of heterochromia in CHS may be related to preganglionic lesions, even though pharmachological pupillary reaction are postganglionic type. It has been reported that Horner's syndrome with a primary preganglionic lesion may behave pharmacologically as if there were a postganglionic lesion. This paradox has been explained by orthograde transsynaptic degeneration of the postganglionic neurons following a preganglionic lesion especially in the neonate. ${ }^{2910}$

An asymmetry of facial flushing with increased body temperature has been reported in patients with unilateral, central or postganglionic lesions in the sympathetic pathway to the face. ${ }^{45}$ This symptom, described in a few patients with $\mathrm{CHS},{ }^{26}$ was the primary complaint in the cases described.

Cutaneous blood vessels are regulated by several mechanisms including neural vasomotor controls and release of vasoactive substances such as VIP, substance $P$, serotonin, or

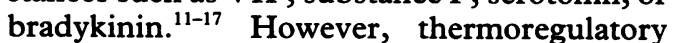
responses of skin vessels are thought to be controlled by sympathetic nervous system, ${ }^{412}$ the mode of which varies in different areas of the body surface. The facial areas can be classified into two groups. In the lips, ears, and nose, thermoregulatory responses of skin vessels, as in the hands, are mediated principally by variations of vasoconstrictor tone. In the scalp, forehead, cheek, neck and chest, as in the forearm, the responses are mediated principally by active vasodilation, although vasoconstrictor nerves are also involved. ${ }^{131416}$ Vasoconstrictor fibres usually operate by releasing norepinephrine at their nerve endings, and vasodilator fibres act possibly by releasing acetylcholine. ${ }^{16}$

In unilateral facial flushing the areas that are not flushed are usually identical to anhidrotic areas. ${ }^{24517}$ Fox et al $^{17}$ concluded that in thermoregulatory flush, active vasodilation is produced mainly by bradykinin resulting from sweat gland activity. But it has been questioned whether this is a sole mechanism of thermoregulatory flushing of the face. ${ }^{416}$ Roddie $^{16}$ suggested that vasodilator and sudomotor sympathetic fibres merge in the skin and release acetylcholine when they are thermally activated. Dissociation between sudomotor and vasomotor functions has been reported in some patients especially with central sympathetic lesions suggesting that each of these functions depends on different fibres. ${ }^{418}$ In case 2, the intact side of the face showed marked flushing and increased skin temperature after exercise. In the affected side, however, there was no facial flushing and the skin temperature decreased after exercise. Similar changes of facial skin temperature was also observed in case 1, though direct measurements were not taken. This reduction of skin temperature in the affected side may be caused by an impaired sympathetic vasodilation and by active vasoconstriction resulting from supersensitivity to circulating catecholamine. My observations suggest that, in CHS with impaired facial sympathetic function, skin vessels under adrenergic sympathetic control might, like the pupillary dilator muscle, become sensitive, and intensify the asymmetry of the facial flushing with increased body temperature.

1 Miller NR, ed. Walsh and Hoyt Clinical Neuro-Ophthal mology. Ed 4, Vol 2. Baltimore: Williams and Wilkins, 1985:503-4.

2 Wienstein JM, Zweifel TJ, Thompson HS. Congenital Horner's syndrome. Arch Ophthalmol 1980;98:1074-8.

3 Hyodo T, Kase M, Shintomi Y. Two cases of congenital Horner's syndrome. Folia Ophthalmol Jap 1983;34: 387-90.

4 Drummond PD, Lance JW. Facial flushing and sweating mediated by the sympathetic nervous system. Brain 1987;110:793-803.

5 Lance JW, Drummond PD, Gandevia S. Harlequin syndrome: the sudden onset of unilateral flushing and sweating. $J$ Neurol Neurosurg Psychiatry 1988;51:635-42.

6 Scarlett HW. Frequency of the Claude Bernard-Horne syndrome. Report of 16 cases. Am J Ophthalmol 1928;11:961-5.

7 Goetz RH. The surgical physiology of the sympathetic nervous system with special reference to cardiovascular disorders. Internat Abstract Surg 1948;87:417-39.

8 Morris JGL, Lee J, Lim CL. Facial sweating in Horner's syndrome. Brain 1984;107:751-8.

9 Weinstein JM, Cutler JJ. Observations on transsynaptic changes in acquired Horner's syndrome. Am JOphthalmol 1983;95:837-8.

10 Black IB, Mytilineou C. Trans-synaptic regulation of the development of end organ innervation by sympathetic neurons. Brain Res 1976;101:503-21.

11 Hyndman OR, Wolkin J. The autonomic mechanism of heat conservation and dissipation. I. Effect of heating the body. Evidence for the existence of capillary dilator nerves in anterior roots. Am Heart J 1941;22:289-304.

12 Folkow B, Ström G, Unväs B. Efferent nervous pathways involved in cutaneous vasodilation induced by activation of hypothalamic heatloss mechanisms. Acta Physiol Scand 1949;17:327-38.

13 Blair DA, Glover WE, Roddie IC. Cutaneous vasomotor nerves to the head and trunk. J Applied Physiol 1961;16:119-22.

14 Fox RH, Goldsmith R, Kidd DJ. Cutaneous vasomotor control in the human head, neck and upper chest. J Physiol 1962;161:298-312.

15 Gonzalez G, Onofrio BM, Kerr FW. Vasomotor system for the face. $J$ Neurosurg 1975;42:696-703.

16 Roddie IC Circulation to 作 Shepherd JT, Abboud FM, Geiger SR, eds. Handbook of Physiology, Sec 2. The Cardiovascular System, vol 3. Peripheral circulation and organ blood flow, Part 1,

17 Fethes. American Physiological Society, 1983:285-317. a a factor in heat vasodilatation. J Physiol 1958;142:219-32.

18 Stead EA, Ebert RV, Romano J, Warren JV. Central 92-107. 